\title{
Tongue arteriovenous malformation with oral haemorrhage treated by embolisation
}

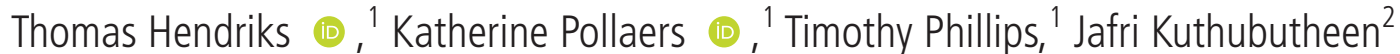

'ENT, Sir Charles Gairdner Hospital, Nedlands, Western Australia, Australia

${ }^{2}$ ENT, Fiona Stanley Hospital, Murdoch, Western Australia, Australia

\section{Correspondence to} Dr Thomas Hendriks; thomas.hendriks@health.wa. gov.au

Accepted 8 May 2020

\section{DESCRIPTION}

A 19-year-old man presented to the emergency department (ED) with haemorrhage from a large right-sided sublingual arteriovenous malformation (AVM). Haemostasis was attained with conservative measures. The patient was transferred to a tertiary centre where MRI, CT angiogram and digital subtraction angiography (DSA) confirmed a large tongue AVM - a rare and often asymptomatic entity but with the potential to cause serious complications. ${ }^{12}$ The patient underwent urgent embolisation of the AVM without further haemorrhage and he has remained well during serial follow-up with the ear, nose and throat (ENT) team 3 months postprocedure.

The patient presented initially to a rural ED with a 4-day history of intermittent small volume oral cavity bleeds without preceding trauma/dental procedures or obvious precipitants. There was no history of similar events or bleeding disorders. He was transferred to the closet tertiary hospital for further investigation and management. The patient's medical history was significant for meningococcal as a young child however he was otherwise fit and well.

On arrival to ED, the ENT team were contacted to assess the patient. On inspection of the oral cavity, a moderate sized clot was noted overlying a submucosal fullness of the right lateral tongue which dislodged during examination. This resulted in large volume haemorrhage managed in ED with

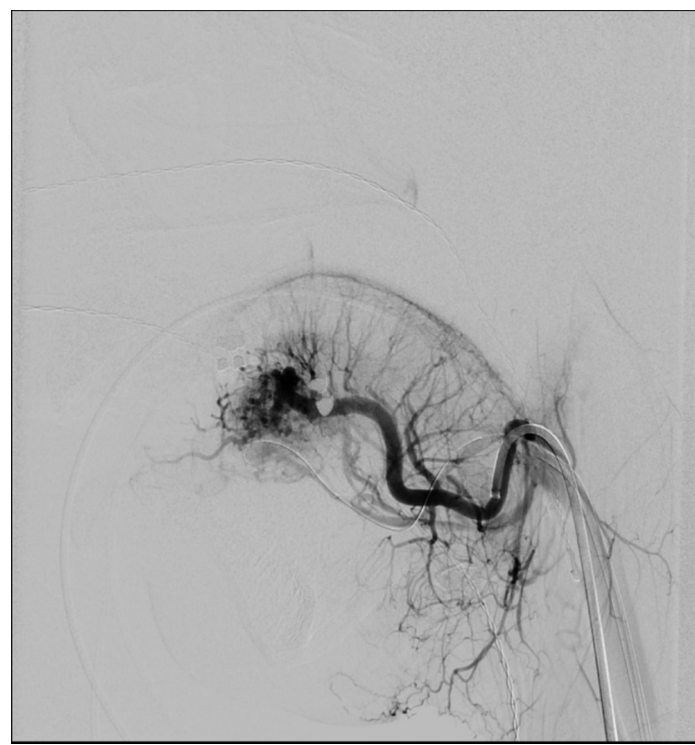

Figure 1 Right lingual artery digital subtraction angiography, lateral projection, prior to embolisation.

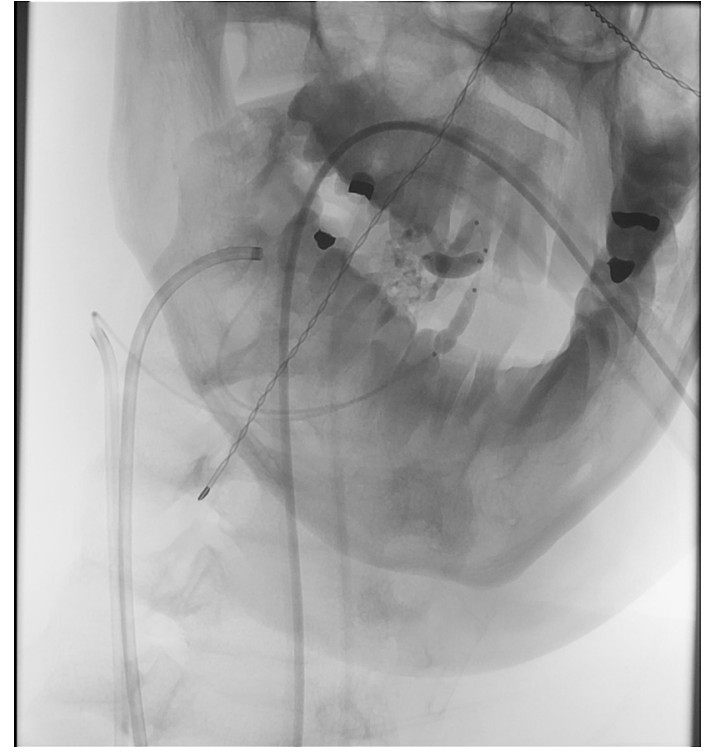

Figure 2 Oblique unsubtracted image demonstrating Microvention Scepter balloons in the lingual artery and lingual vein.

epinephrine soaked gauze packing to the region, epinephrine injection around the bleeding point and bipolar diathermy. His observations remained stable throughout. Blood tests revealed a haemoglobin drop of $17 \mathrm{~g} / \mathrm{L}(148 \mathrm{~g} / \mathrm{L}$ to $>131 \mathrm{~g} / \mathrm{L}$ postbleeding episode), coagulation profile was unremarkable and a group and antibody screen was collected.

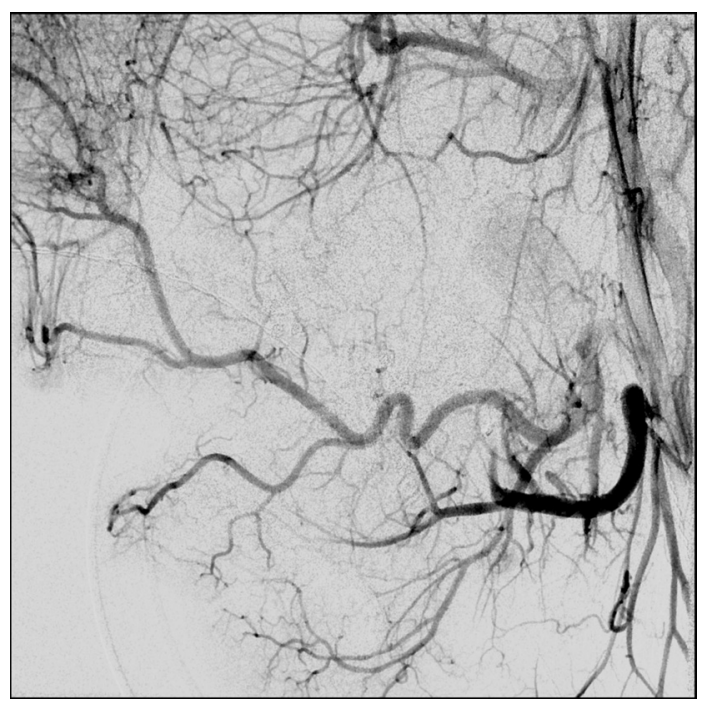

Figure 3 Right external carotid artery digital subtraction angiography, lateral projection, demonstrating complete occlusion. 
The patient underwent urgent imaging and DSA to assess for an underlying aetiology. A large diffuse AVM nidus in the ventral aspect of the right side of the body of the tongue was demonstrated (see figure 1). Arterial supply to the AVM was noted to be exclusively from deep branches of the right lingual artery and multiple early filling and enlarged deep lingual veins drained the AVM into the left jugular vein. The patient was further transferred to a facility whereby neuro-interventional radiology services were provided and underwent an uncomplicated arterial and venous liquid embolisation using $25 \%$ polyactide-co-glycolide and polyhydroxyethylmethacrylate dissolved in dimethyl sulfoxide, injected into the AVM nidus from both the arterial and venous catheters (see figure 2). Complete nidal occlusion was

\section{Learning points}

- Arteriovenous malformations (AVMs) outside the central nervous system (CNS) are rare and called extracranial AVMs, they are often asymptomatic however serious sequelae can include rupture and haemorrhage which does not often present until early adulthood.

- Treatment typically includes complete surgical resection to reduce the risk of recurrence with preceding embolisation due reduce the risk of intraoperative bleeding, however management is largely dependent on the location and size of the AVM.

- We present the rare case of a large extracranial sublingual AVM that must be considered and investigated further in cases of patients presenting with spontaneous oral cavity haemorrhage given the potential for serious complications if left untreated. demonstrated following embolisation without penetration to the tongue surface branches (see figure 3). Embolisation of AVMs is an effective non-surgical treatment for disease control especially in the acute setting however recurrence and progression of disease can occur. ${ }^{34} \mathrm{He}$ was monitored for 24 hours postembolisation without complications and was discharged with outpatient ENT follow-up organised. His most recent follow-up 3 months later was uneventful without further haemorrhages and there was stability of his submucosal fullness right ventrolateral tongue.

Contributors TH prepared the manuscript and was involved in the management of the patient. KP was the initial surgical registrar involved in the patients care. TP was the operating interventional radiologist whom performed the embolisation. JK was the admitting consultant when the patient initially presented to hospital.

Funding The authors have not declared a specific grant for this research from any funding agency in the public, commercial or not-for-profit sectors.

Competing interests None declared.

Patient consent for publication Obtained.

Provenance and peer review Not commissioned; externally peer reviewed.

\section{ORCID iDs}

Thomas Hendriks http://orcid.org/0000-0002-7676-6171

Katherine Pollaers http://orcid.org/0000-0002-1351-5236

\section{REFERENCES}

1 Liu AS, Mulliken JB, Zurakowski D, et al. Extracranial arteriovenous malformations: natural progression and recurrence after treatment. Plast Reconstr Surg 2010;125:1185-94

2 Chimona TS, Papadakis CE, Hatzidakis AA, et al. Arteriovenous malformation of the floor of the mouth: a case report. Eur Arch Otorhinolaryngol 2005;262:939-42.

3 Gharaibeh TM, Safadi RA, Rawashdeh MA, et al. Plunging arteriovenous malformation in the floor of the mouth: a case report. Br J Oral Maxillofac Surg 2010;48:e35-7.

4 Richter GT, Suen J, North PE, et al. Arteriovenous malformations of the tongue: a spectrum of disease. Laryngoscope 2007;117:328-35.

Copyright 2020 BMJ Publishing Group. All rights reserved. For permission to reuse any of this content visit

https://www.bmj.com/company/products-services/rights-and-licensing/permissions/

BMJ Case Report Fellows may re-use this article for personal use and teaching without any further permission.

Become a Fellow of BMJ Case Reports today and you can:

- Submit as many cases as you like

- Enjoy fast sympathetic peer review and rapid publication of accepted articles

Access all the published articles

- Re-use any of the published material for personal use and teaching without further permission

Customer Service

If you have any further queries about your subscription, please contact our customer services team on +44 (0) 2071111105 or via email at support@bmj.com.

Visit casereports.bmj.com for more articles like this and to become a Fellow 